Historic, archived document

Do not assume content reflects current scientific knowledge, policies, or practices. 



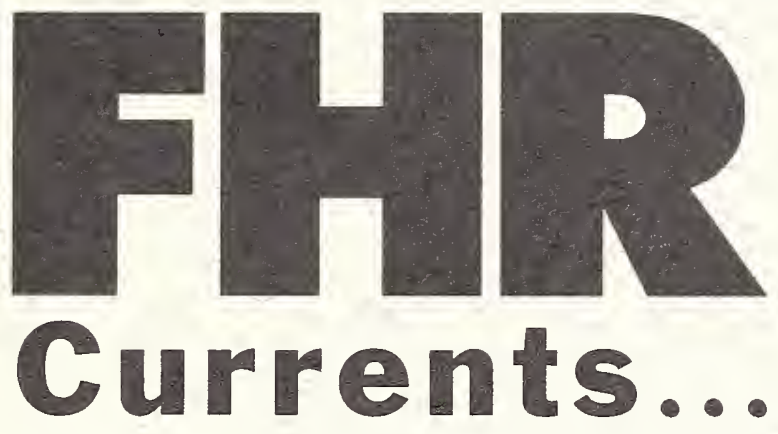

Fish Habitat Relationships Technical Bulletin Number 14 December 1993

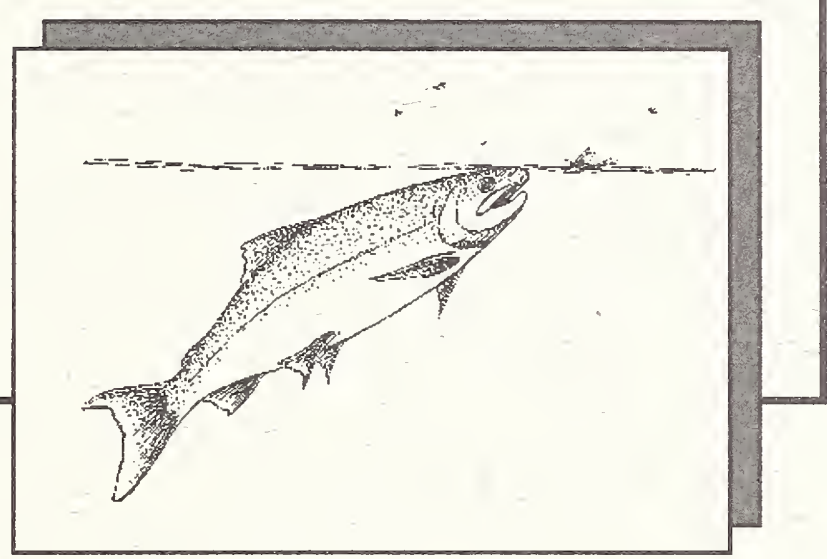

\title{
Consideration of Extinction Risks for Salmonids
}

\author{
Bruce Rieman, Danny Lee, Jack Mclntyre, \\ Kerry Overton, and Russ Thurow \\ USDA Forest Service \\ Intermountain Research Station \\ Work Unit 4203 \\ Boise, Idaho
}

\begin{abstract}
Under the National Forest Management Act of 1979, the USDA Forest Service is charged with maintaining viable populations of all existing native vertebrate species on lands they administer. Accomplishment of this responsibility requires complete assessment of all federally authorized, funded, or implemented projects that may jeopardize the continued existence of a species. An understanding of the processes of extinction and the characteristics of populations that make them more or less likely to persist is fundamental to such assessments. We review processes contributing to extinction and characterize them as deterministic, stochastic, and genetic. Factors that strongly influence risks of local and regional extinction include replication, dispersal and connection among populations representing a regional metapopulation. Project planning and assessments must address habitat disruption and population responses at both the local and regional scale. Maintaining strong populations in the best possible habitats throughout the landscape and preserving the ecological processes characteristic of metapopulations are the best hedges against extinction.
\end{abstract}

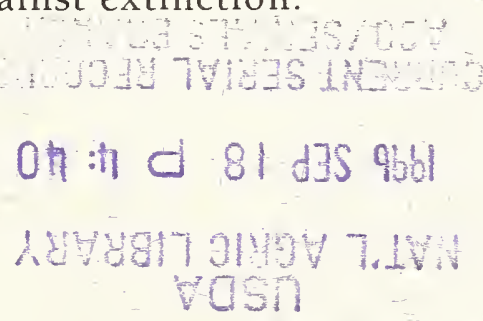




\section{FHR Currents Purpose}

The USDA Forest Service Fish Habitat Relationships Program was established to further the development of fisheries technology and transfer this technology to field biologists. With ever increasing demands for natural resources, protection and management of aquatic communities requires biologists to be knowledgable of current research findings and state-of-the-art techniques. The purpose of FHR Currents is to provide a vehicle to quickly disseminate information important to field-level biologists in the USDA Forest Service.

\section{Submissions:}

If you wish to submit a paper for publication in FHR Currents, please contact the following people for information and guidelines:

Jerry Boberg/Dave Fuller

Technical Editors

(707) $441-3669$

Stephanie Gomes

Editor/Designer

(707) $441-3550$

Six Rivers National Forest

Fisheries Department

1330 Bayshore Way

Eureka, CA 95501

Forest Service Fish Habitat Relationships Program Leaders or Representatives

National FHR Program

Jeffrey L. Kershner

Washington Office

Fish \& Wildlife Department

Utah State University

Logan, UT 84322-5210

\section{Region 1}

Kathy Moynan, Northern Region

(Anadromous Fish Program)

Nez Perce National Forest

Route 2, Box 475

Grangeville, ID 83530

Brian Sanborn, Northern Region

(Resident Fish Program)

Deerlodge National Forest

Federal Building, Box 400

Butte, MT 59703

\section{Region 2}

R. Nick Schmal, Rocky Mountain Region Wildlife, Fish \& Botany Staff

Univ. of Wyoming, College of Agriculture P.O. Box 3354

Laramie, WY 82071-3354

\section{Region 3}

Bryce Rickel, Southwest Region

Wildlife, Fish \& Botany Staff

Federal Building

517 Gold Avel, S.W.

Albuquerque, NM 87102

\section{Region 4}

Seona L. Brown, Intermountain Region Wildlife, Fish \& Botany Staff

32425 th St.

Ogden, UT 84401

\section{Region 5}

Jerry Boberg, Pacific Southwest Region

(Anadromous Fish Program)

Six Rivers National Forest

1330 Bayshore Way

Eureka, CA 95501

Jeffery Reiner, Pacific Southwest Region (Resident Fish Program)

Lake Tahoe Basin Management Unit

870 Emerald Bay Rd., Suite 1

South Lake Tahoe, CA 96150

\section{Region 6}

Deborah Konnoff, Pacific Northwest Region Wildlife, Fish \& Botany Staff

333 S.W. Ist Ave., P.O. Box 3623

Portland, OR 97208

\section{Region 8}

Cindy A. Williams, Southern Region Wildlife, Fish \& Botany Staff

1720 Peachtree Rd.

N.W. Atlanta, GA 30367

\section{Region 9}

Don Hair, Northeast Region

Nicolet National Forest

Federal Building, 68 South Stevens

Rhinelander, WI 54501

\section{Region 10}

Ron Dunlap, Alaska Region Wildlife, Fish \& Botany Staff Federal Office Building, Box 21628 Juneau, AK 99802-1628

\section{Intermountain/Northern Region}

Kerry Overton, Fish Research Work Unit Intermountain Research Station

316 E. Myrtle St.

Boise, ID 83702

\section{Associates}

\section{Glenn Chen}

Fisheries Biologist/Monitoring Specialist, USDA Forest Service

Fish \& Wildlife Department

Utah State University

Logan, UT 84322-5210

\section{David Fuller}

Fisheries Biologist, USDA Forest Service

Six Rivers National Forest

1330 Bayshore Way

Eureka, CA 95501

Ken Roby

Hydrologist, USDA Forest Service

Pacific Southwest Experiment Station P.O. Box 245

Berkeley, CA 94701-0245

Larry Schmidt

Stream Systems Technology Center USDA Forest Service

Rocky Mountain Experiment Station 240 W. Prospect

Fort Collins, CO 80526-2098

Mark Vinson

Hydrologist/Monitoring Specialist,

USDI Bureau of Land Management

Fish \& Wildlife Department

Utah State University,

Logan, UT 84322-5210 


\section{Introduction}

Assessing the viability of individual fish populations is a major problem for many fisheries biologists. Unfortunately, there is little quantitative support or guidance for such assessments. Extinction risks for salmonids are influenced by complex and interacting factors that are often difficult, if not impossible, to identify and measure. Despite this difficulty, understanding the nature of the extinction process can lead to management prescriptions that minimize risks to local populations. Theoretical insights from the developing field of conservation biology can provide guidance to population managers. In this report, we review factors influencing the persistence of populations and suggest means for managing resident trout and char populations to mitigate extinction risks.

\section{The Basics of Extinction}

The first step in discussing population extinction is to define population: For this discussion, a population is a group of animals that has a high probability of mating among its members relative to mating with members of other populations of the same species. For example, a trout population might consist of a group of fish that spawn and rear in a specific tributary but not in the mainstem. By virtue of homing or stream residency, they are isolated to various degrees from fish in other tributaries. A collection of such populations that interact through the exchange of individuals is termed a metapopulation. Metapopulations are associated with large watersheds, lakes, or river basins -- depending on the level of connection among streams and the straying or dispersal rates and distances typical of each species. When habitat is lost or streams are blocked, metapopulations may become fragmented into isolated local populations.

Commonly, extinction refers to the loss of a species. Extinctions also occur at the level of a local population and at regional levels represented by metapopulations. Because Forest Service policy directs the maintenance of a species throughout its range, local and regional extinctions are important to fisheries biologists. We focus our discussion on extinction processes relevant to local populations and then consider metapopulation dynamics that are important to both local and regional persistence.

Extinction occurs when population losses (defined as the per capita death or emigration per unit time) exceed population gains (defined as the per capita reproduction or immigration per unit time) long enough to extinguish the population. The population growth rate $(\boldsymbol{R})$ is defined as the natural log of the birth rate minus the death rate. When $\boldsymbol{R}$ is negative, the population declines; if $\boldsymbol{R}$ is positive, the population increases. The mechanisms leading to extinction can be characterized in three general categories: deterministic, stochastic, and genetic (Leigh 1981; Gilpin and Soulé 1986; Gilpin 1987; Shaffer 1987; Shaffer 1991) which can operate in complex combinations. In the following, we will discuss each of these in turn.

\section{Characterization of Risks}

\section{Deterministic Processes}

Deterministic extinctions occur with the cumulative loss or otherwise permanent change of a critical component in the species' environment (Gilpin and Soulé 1986). Such changes result in progressive increases in the population death rate, decreases in the population birth rate, or both. If the environment changes sufficiently, natural compensatory mechanisms, which tend to increase the birth rate as the death rate increases, can be overwhelmed. This leads to a negative expectation of $\boldsymbol{R}$. Despite occasional increases in the population due to stochastic factors (see below), the population will move inexorably towards extinction.

For salmonids, a variety of factors might contribute to deterministic extinction. Bull trout populations might decline, for example, with the elimination of pools or woody debris that are necessary as overwinter habitat; or with an increase in fine sediments that degrade spawning 
habitats and lead to increased mortality of incubating embryos. Salmon populations have declined with increasing mortality at dams in the migratory corridor. Alternatively, competition or predation might increase with the introduction of exotics. Changes that might be tolerated separately may lead to extinction in combination. Displacement of bull trout by brook trout, for example, may occur more commonly in degraded habitat. Relatively subtle changes in habitat quality may favor one species over another (Everest et al. 1987). Mortality from some causes can increase as populations become smaller, even with no further change in the environment. Such depensatory effects may be particularly relevant for salmonids (Peterman 1977; Peterman and Gatto 1978; Rieman and Apperson 1989; Rieman and Myers 1991).

A population's response to environmental change depends on somatic growth, mortality, fecundity, longevity, and age at maturity. In combination, these factors determine the reproductive potential of the population, and thus its ability to compensate for increased levels of mortality. Given similar age structures, sex ratios, mortality, and maturation rates, for example, populations with higher reproductive potentials should be more resistant to disturbance. A fluvial population of cutthroat trout that matures at age four and 400 $\mathrm{mm}$ will likely have a higher reproductive potential than a resident population of cutthroat trout that matures at age four and $200 \mathrm{~mm}$.

Additional or cumulative stresses will progressively decrease the compensatory capacity of a population. Simply put, habitat disruption that results in lower survival or growth at one stage means that less mortality can be sustained at another stage if the population is to maintain its current numbers. Most populations can absorb some increased mortality, hence the ability to withstand harvest. Cumulative mortality related to habitat loss reduces that reserve. Clearly, all populations are not equal in their ability to absorb additional stresses -- but we cannot accurately estimate the differences. Any habitat change that irreversibly reduces survival or growth at any life stage increases the risk of deterministic extinction.
Much, if not most, of the loss of salmonid populations probably results from habitat change and other actions (e.g., fishing regulations, species introductions, pollution) that induce deterministic responses. These problems are well known among fisheries biologists. Restrictive angling regulations and habitat management efforts are often used to increase survival and mitigate such risks in individual populations. The long term declining trends in many populations suggest that such efforts are not always successful.

\section{Stochastic Processes}

Less familiar to fisheries biologists are risks associated with stochastic processes, or chance events. Such processes result in unpredictable fluctuations in population numbers. At times, such fluctuations can portend disaster for populations, especially if the populations are very small. Stochastic processes generally are grouped into two categories, demographic and environmental, depending on their origin. For example, Nisbet and Gurney (1982) distinguish the two as:

(a) Demographic stochasticity, which is the name given to fluctuations that arise because populations contain a discrete number of members, with population changes being caused by a succession of individually unpredictable births and deaths;

(b) Environmental stochasticity, which is the name properly applied to a periodic environmental variation and often applied loosely to the resulting population fluctuations.

Demographic stochasticity arises from small magnitude differences among individuals that might ordinarily be viewed as similar. In population models, demographic stochasticity is introduced through a discrete sampling process. For example, survival of a group of $N$ fish in a given year might be modeled as $X$ successes in $N$ trials where $X$ is the number surviving. If $P$ is the probability of success in each trial (i.e., probability of survival), the expected number surviving would 
be $(\boldsymbol{N} \cdot \boldsymbol{P})$. The difference between $\boldsymbol{X}$ and $(\boldsymbol{N} \cdot \boldsymbol{P})$ is demographic stochasticity, often referred to as the sampling error. The ratio of the expected sampling error to the expected outcome (the coefficient of variation) decreases as the sample size increases. Thus, this type of variation is most important at low population abundances. Demographic stochasticity is considered inconsequential unless population sizes are very small (i.e., 20 adults) (Leigh 1981; Shaffer and Samson 1985; Quinn and Hastings 1987; Shaffer 1987).

Environmental stochasticity includes chronic and catastrophic fluctuations of higher amplitude (Shaffer 1987; Shaffer 1991). Such variations in survival and birth rates can be attributed to normal variability in such characteristics as temperature and stream flow, or low frequency, extreme events such as flood, drought, fire storms and debris torrents.

The variance in the population growth rate resulting from the combination of demographic and environmental stochasticity interacts with population size to determine the probability of extinction over a given time period (Dennis et al. 1991; Leigh 1981; Boyce 1992). The expected time to extinction decreases as population size decreases and as the variation in the population growth rate increases. Small populations tend to vary relatively more than large populations (Gilpin and Soulé 1986). They are likely to experience high temporal variation, lower genetic and phenotypic diversity, and have few refuges available (Gilpin and Soulé 1986; Shaffer 1987; Saunders et al. 1990).

Population viability analyses, based in both simulation and analytic models, provide estimates of stochastic risks for a variety of taxa (see for example, Shaffer and Samson 1985; Dennis et al. 1991; Stacey and Taper 1992). Such efforts require data that often are not available for many populations of salmonids. Results for a variety of species, however, suggest that populations isolated from other populations face higher risks through stochastic effects. For example, our analysis (Rieman and McIntyre 1993) of local bull trout populations indicates that few have a high probability of persisting for 100 years in isolation from other populations. Such analyses also suggest that extinction risks for local, isolated populations increase sharply as population sizes drop below roughly 1,000-2,000 total individuals (Figure 1).

Historically, stochastic processes may have posed little threat to most local and regional salmonid populations. However, with the loss of habitat, many populations have declined dramatically in size and have been restricted to marginal or highly variable habitats, thus increasing the risk from stochastic factors. Habitat change can influence not only the amount of environmental variation, but also the sensitivity of a population to that variation. Populations in complex habitats should be more stable than populations in simple or restricted habitats because they have more refuges from extreme events and greater capacity to buffer the effects of environmental change (Schlosser 1982; Saunders et al. 1990; Sedell et al. 1990; Schlosser 1991; Pearson et al. 1992). Even without any further habitat loss, we anticipate further loss of already restricted populations.

\section{Genetic Risks}

Conservation of a species depends on protection of its genetic diversity. The consequence of losing diversity is loss of genetic combinations, some of which may be crucial to survival in highly variable environments. Although adaptations to local conditions are difficult to identify, their presence is generally supported by data (for example, Hynes et al. 1981; MacLean and Evans 1981). At present, available data do not provide a basis for specifying the minimum amount of genetic diversity that must be maintained to ensure persistence of salmonid populations.

The literature is replete with arguments that one cannot define general guidelines for the minimum number of organisms needed in a population to mitigate the effects of genetic loss. Soule (1987) argues, however, that the public deserves guidance from the scientific community so that conservation programs can proceed. He proposes the " $50 / 500$ " rule: in a completely closed population, an effective population size of 50 is 


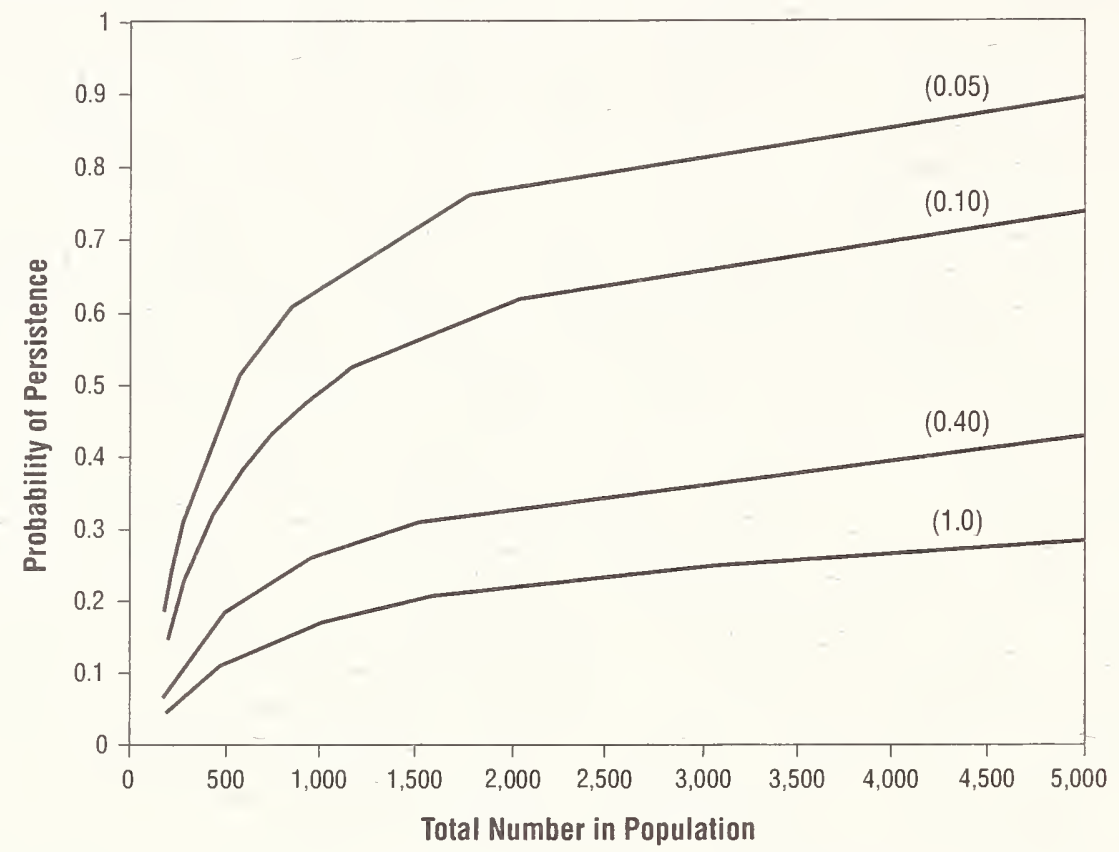

Figure 1. Estimated probability that a hypothetical population will persist above a minimum threshold of 20 adults for 100 years given an initial population size and the variance ( ) in the annual population growth rate. Populations were assumed to be fluctuating around some equilibrium. Estimates of variances are not available for most salmonid populations but existing data suggest that many may range from 0.05 to 0.50 or higher. These results indicate that risks of dropping below the threshold increase sharply with initial population sizes less than 1,000 to 2,000 total individuals. Thresholds do not represent true extinction but a point where risks through demographic stochasticity, lost genetic variation and inbreeding, or depensatory mortality may make recovery unlikely without support from other populations. The estimates follow the method of Dennis et al. (1991) as outlined in Rieman and Mclntyre (1993).

needed to prevent excessive rates of inbreeding, but 500 is needed to maintain the genetic variation necessary for long term adaptation. Effective population size refers to the level of genetic variability represented in the breeding individuals and not to the total population size; the effective number may equal three-quarters or less of the actual number (Salwasser and Marcot 1986; Falconer 1989). Nelson and Soulé (1987) suggested that genetic variation can be lost with fewer than 5,000 total individuals.

Historically, much of the thinking in species conservation focused on genetic issues associated with small population size and isolation (Franklin 1980; Shaffer 1991). More recent work suggests that many populations are at higher risks from environmental stochasticity or catastrophic events than through inbreeding or the loss of genetic variation (Lande 1988; Shaffer 1991; Stacey and
Taper 1992). It seems likely that management prescriptions taken to minimize stochastic and deterministic effects will at the same time minimize genetic risks.

Although we have classified the risks of extinction in three general areas, it is important to recognize that the processes of extinction do not operate independently. Genetic restriction, for example, may reduce fitness and increase sensitivity to environmental variation. Cumulative habitat changes that eliminate or isolate segments of populations may increase both demographic and environmental stochasticity because of lower numbers and lower diversity in population structure or distribution. Those same habitat changes might increase mortality directly by restricting the population to less productive habitat, also leading to increased deterministic risk. 


\section{Metapopulation Dynamics}

If the odds seem stacked against the local population, how then does one explain the apparent persistence in nature of large numbers of relatively small populations in highly variable environments? One possible mechanism contributing to population persistence involves organization of populations at a higher level. An expanding literature in conservation and population biology suggests that large-scale spatial structure and dispersal mechanisms are critical to the persistence of populations of many taxa (Gilpin 1987; Shaffer 1987; Hanski 1991; Hanski and Gilpin 1991; Sjogren 1991; Boyce 1992). Many species exist in spatially heterogeneous environments with local groups of animals associated with patches of suitable habitat. These local groups are more likely to interact and interbreed among themselves than with other groups, but exchange of individuals occurs through a range of dispersal mechanisms. Populations within populations in this context are again defined as metapopulations in the emerging jargon of conservation biology (Shaffer 1987; Hanski and Gilpin 1991).

Theoretically, the diversity of local populations in variable environments conveys stability to the larger metapopulation. Local extinctions are a natural if not common part of the regional population dynamics for many species (Hanski 1991; Hanski and Gilpin 1991; Sjogren 1991). Multiple component populations in complex habitats spread the risk of synchronous extinctions (Morrison and Barbosa 1987; Quinn and Hastings 1987). Stronger populations provide sources for recolonization (Brown and Kodric-Brown 1977; Sjogren 1991), or support of other weaker populations through dispersal of surplus animals (Hanski 1985; Pulliam 1988) (Figure 2).

Metapopulation dynamics may be particularly important to the persistence and recovery of populations following catastrophic events (Yount and Niemi 1990), but probably play a role in normally variable environments as well. The probabilities of persistence and relative stability of the metapopulation are strongly influenced by the sizes, spatial distribution, temporal variation and synchrony, and dispersal among the component populations (Fahrig 1990; Hanski 1991; Sjogren 1991; Doak et al. 1992).

Populations of salmonids have features characteristic of metapopulations. Spawning and early rearing often occur in streams tributary to larger river or lake systems. Homing and fidelity to nursery areas creates some isolation among populations within streams and represent the basis of the stock concept (Ricker 1972). Local adaptations provide further evidence of isolation in a heterogeneous environment. Dispersal among groups may be maintained through the straying of migrating adults (Simon 1972; Labell 1992; Reisenbichler et al. 1992), density-dependent displacement of individuals (McMahon and Tash 1988; Northcote 1992), or maintenance of pioneering or colonizing phenotypes (Northcote 1992).

\section{Implications for Fisheries Management}

Metapopulation dynamics are important considerations in conservation planning and species maintenance and recovery efforts (Murphy and Noon 1992; Noon and McKelvey 1992).

There has been some application of these ideas to aquatic environments and fish populations (for example, Sheldon 1988; Moyle and Sato 1991; Reeves and Sedell 1992). There is a general consensus that preserving phenotypic and genetic diversity requires maintaining populations through a wide geographic range in a variety of habitats (Allendorf and Leary 1988; Leary et al. 1991; Moyle and Sato 1991; Reeves and Sedell 1992). Diversity in life-history characteristics may be critical to the persistence of and dispersal of populations in changing or variable environments (Gross et al. 1991; Northcote 1992; Titus and Mosegaard 1992).

For the most part, however, management and research of interior salmonid populations have continued to focus on the intra-population processes of recruitment, mortality and growth, and production or yield. Management and 


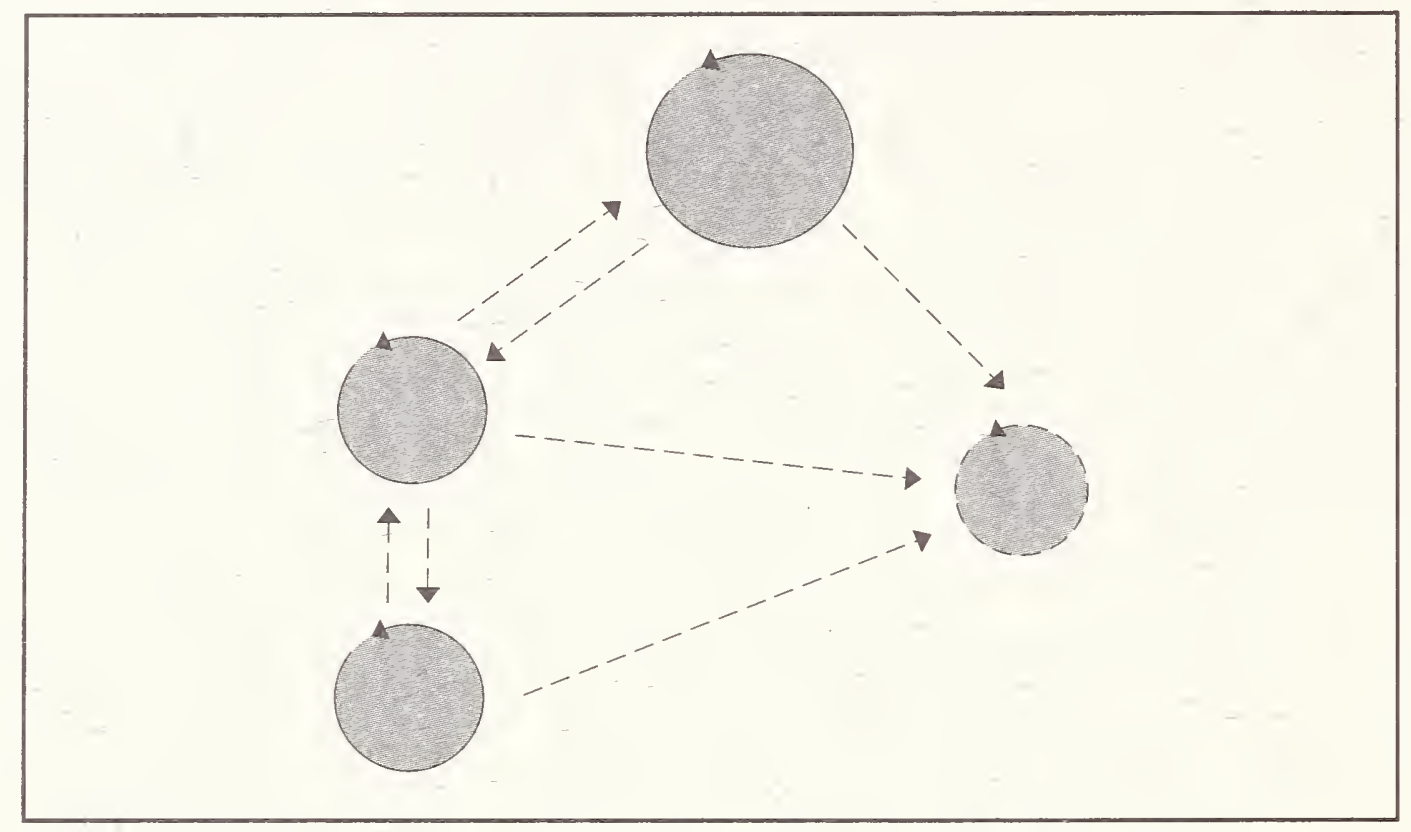

Figure 2. Schematic representation of a metapopulation. Size of the circle represents the relative size of a population and the potential for emigration of individuals. Arrows represent the pathways of exchange among populations. The broken circle represents a population that has a high probability of local extinction, and is likely to persist only through support from other populations.

research have typically focused on characteristics of individual habitat units or stream reaches, and the links between distribution, abundance, and survival of fish at that scale (see Fausch 1988). Growing attention has been placed on consideration of fish habitat relations from a larger scale (Frissell 1993; Frissell et al. 1993); but little is known about the links between spatial diversity in habitat characteristics among streams and the corresponding spatial diversity in the characteristics and dynamics of populations. Similarly, little is known about how populations interact via migration and dispersal. Concern for, and the relative importance of, individual populations is likely to be based more on the relative size or potential yield of a population than on its contribution to stability or diversity of the whole (though the two may be related). For example, marginal environments and discrete life history forms are often overlooked in management decisions focused on the dominant or most productive stocks (Northcote 1992; Wright 1993).

Land-use management and development influence metapopulation processes. Migration, dispersal, and the connection among populations are influenced by changes in hydrologic and temperature patterns, water diversions and dams, channel conditions or barriers, and the distance among remaining populations and suitable habitats. In heavily disturbed environments, populations are isolated or clustered in undisturbed headwater areas (for example, Mullan et al. 1992) (Figure 3). Invasion by exotics may be hastened by habitat disruption (Hobbs and Huenneke 1992; Markle 1992; Mullan et al. 1992) and may produce further isolation or local extinction through competitive displacement (Leary et al. 1991; Mullan et al. 1992).

Conventional forest management can compromise the metapopulation structure by changing the natural mosaic of conditions in which it evolved. Under conventional management, habitat disruption is often spread widely throughout a basin to minimize impacts in any single stream. The use of habitat thresholds or levels of acceptable disturbance is likely to create more homogeneous conditions among streams that cluster about or below the threshold than a more natural range of habitat conditions. Under the former condition, the diversity, resilience, and 
resistance to disturbance of all populations may be compromised, while the synchrony in response to disturbance is increased. When habitat disruption is spread among all populations, all populations are more likely to decline during unfavorable periods in the regional environment (for example, drought). Severe or prolonged conditions increase the potential for regional extinction.

Since forest management influences salmonid population persistence at both local and regional scales, planning and project assessments must address both. Tables 1 and 2 outline the relative risks of extinction associated with characteristics of both local and regional populations. A low risk of extinction means that a population has a high probability (for example, $>95 \%$ ) of persisting through the period relevant to forest management (100 to 200 years), given existing or improving conditions. We judge a population at high risk of extinction as one with less than a 50\% chance of persisting through the same period.
Our attempt to represent the risks for any population characteristic assumes that all other characteristics would represent a low risk. Though there is no exact way to combine the risks presented here, the additive model provides a suitable first approximation. For example, a population at moderate risk through several processes is likely to be at high risk overall.

We believe maintaining strong populations in the best possible habitats throughout the landscape and preserving metapopulation structure and function are the best hedges against extinction. Conservation goals that include maintaining spatially dispersed, high quality habitats will be more effective than goals based solely on estimates of minimum viable population sizes (see Boyce 1992), or goals that allow disruption of all streams. While more work is necessary to describe the appropriate scale for sustaining different species and in different environments, the creation or maintenance of a more natural mosaic of habitat conditions should commence wherever possible.

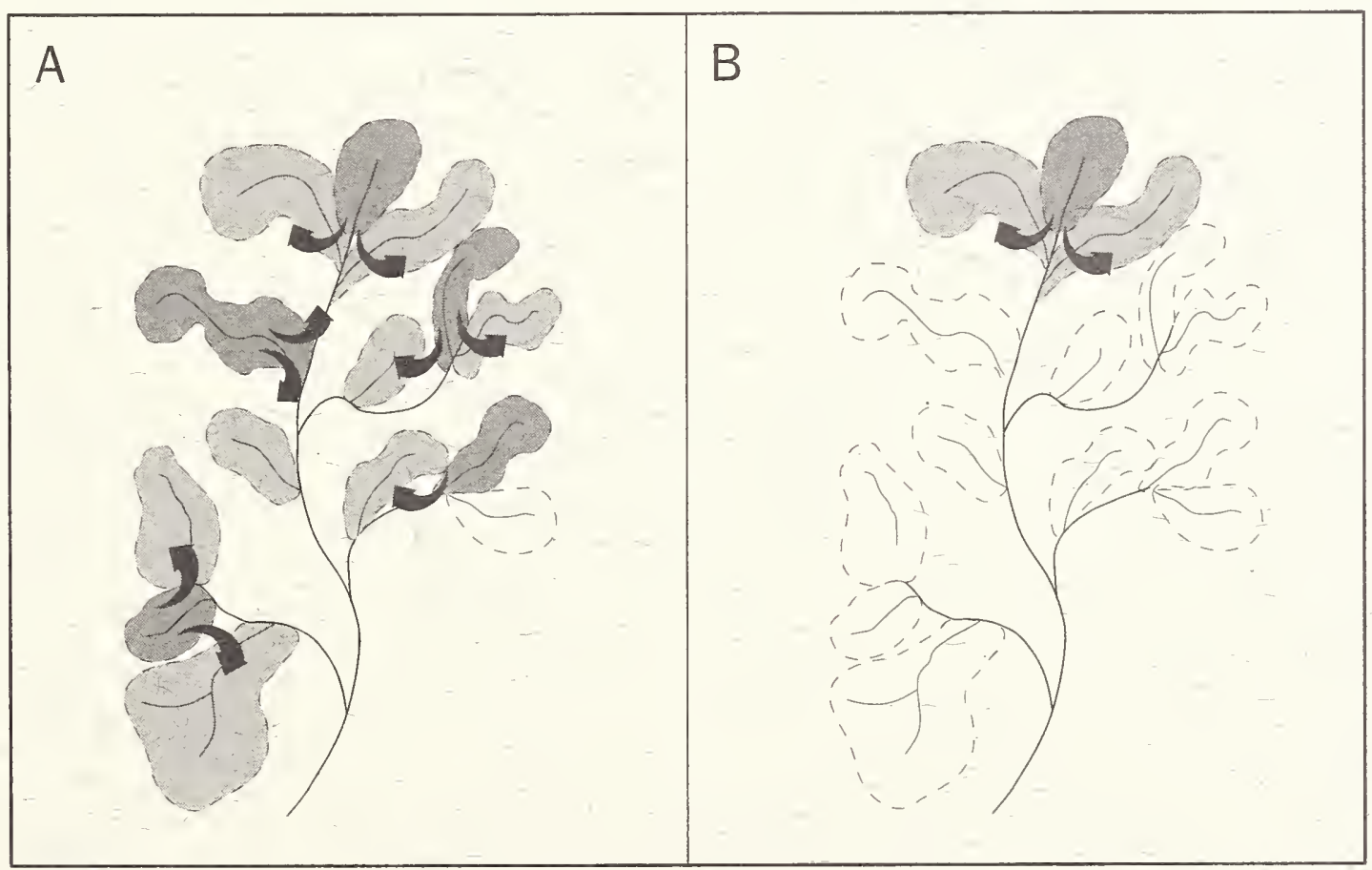

Figure 3. Hypothetical representation of the distribution of salmonid populations within undisturbed $(A)$ and disturbed (B) basins. The darkest shading represents the best habitats supporting the strongest populations with potential for dispersal to and support of other surrounding populations. The lighter shading represents intermediate or disrupted habitats that support fish either because of support from other populations or because habitat is still suitable over the short term. The unshaded areas represent disrupted habitats that support no fish. The arrows represent dispersal among populations. Metapopulation theory suggests that persistence throughout the region may be strongly influenced by the distribution of strong populations. 


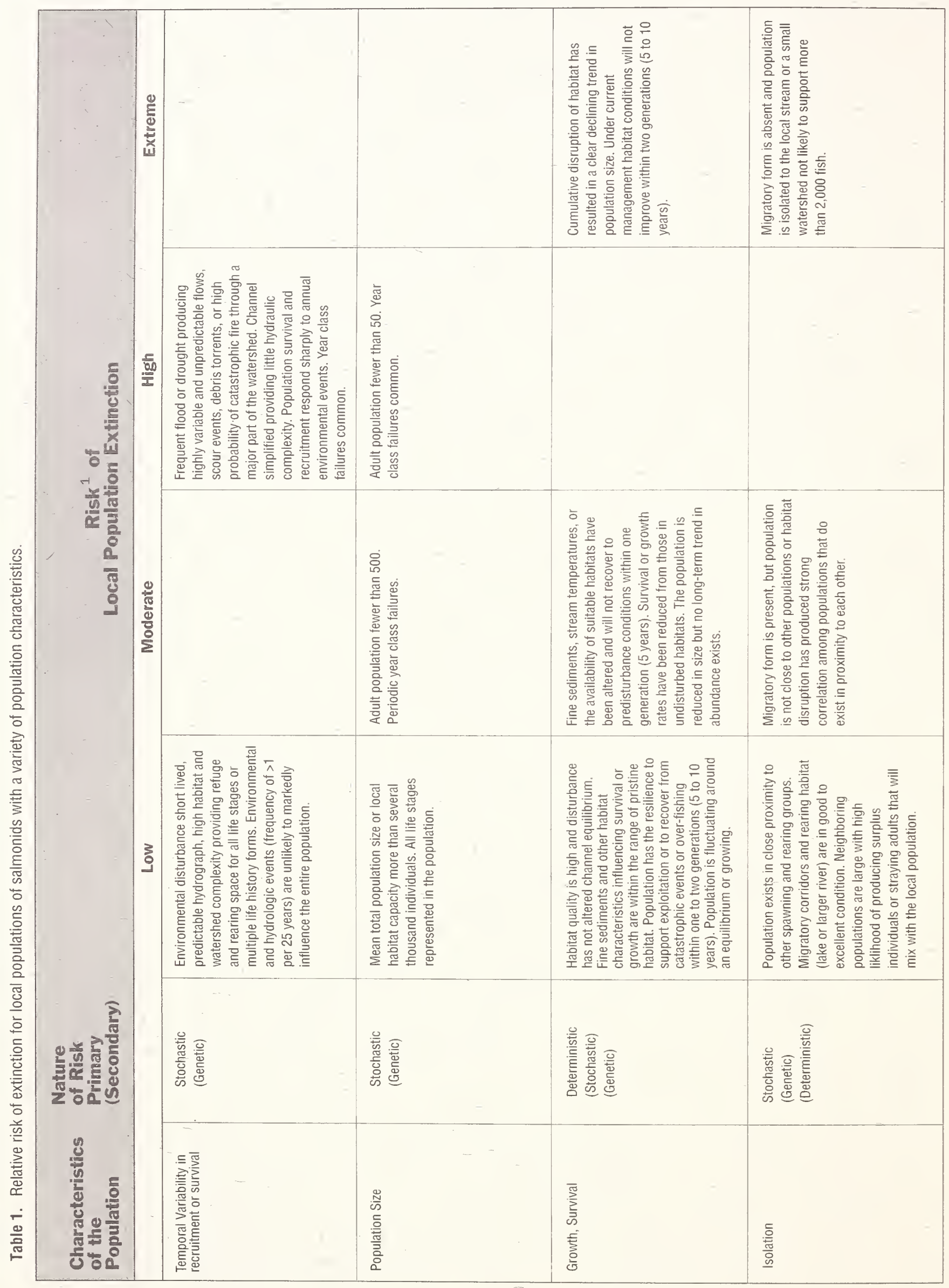




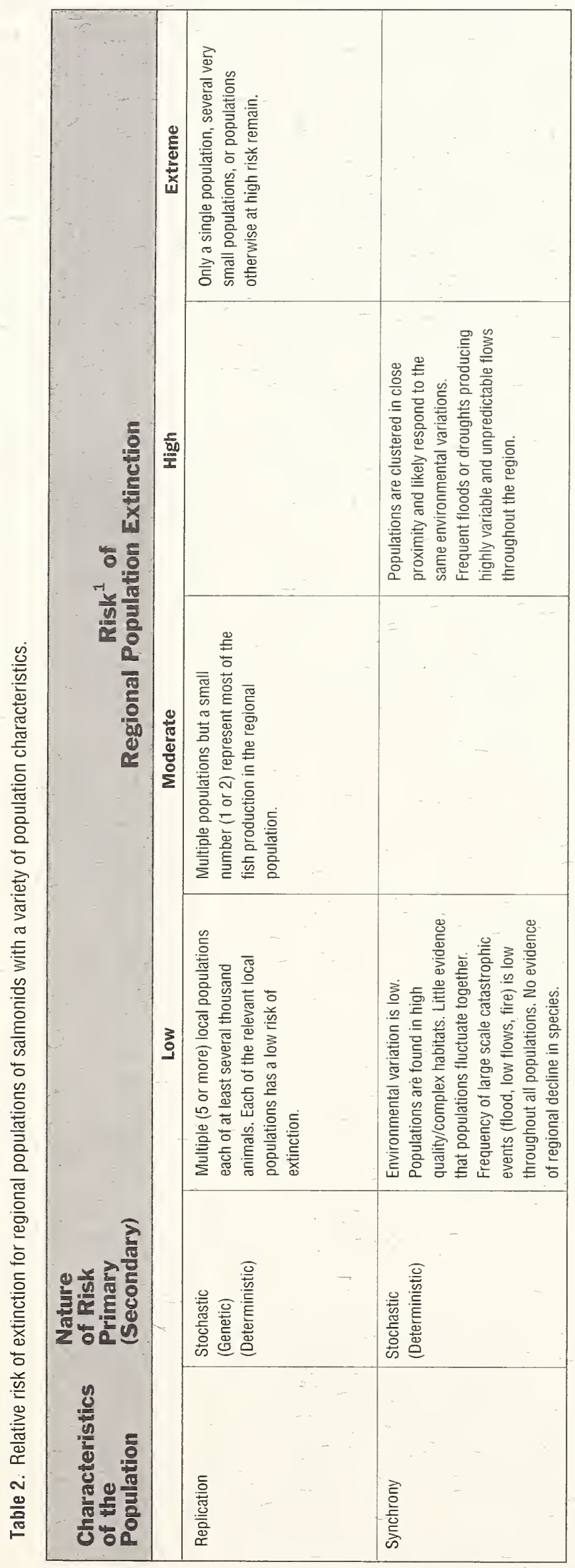

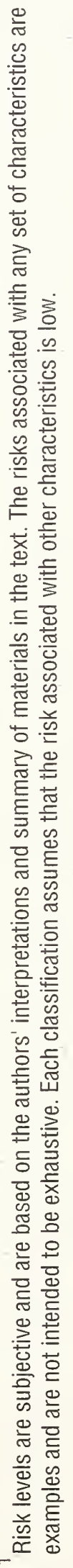




\section{Acknowledgements}

Debby Myers and Shari Whitwell prepared graphics and provided text and manuscript review. A number of people provided important technical review and comment and contributed in preparation of the manuscript.

\section{Literature Cited}

Allendorf, F.W., and R.F. Leary. 1988. Conservation and distribution of genetic variation in a polytypic species, the cutthroat trout. Conservation Biology 2:170-184.

Boyce, M.S. 1992. Population viability analysis. Annual Review of Ecology and Systematics 23:481-506.

Brown, J.H., and A. Kodric-Brown. 1977. Turnover rates in insular biogeography: effect of immigration on extinction. Ecology 58:445-449.

Dennis, B., P.L. Munholland, and J.M. Scott. 1991. Estimation of growth and extinction parameters for endangered species. Ecological Monographs 6:115-143.

Doak, D.F., P.C. Marino, and P.M. Kareiva. 1992. Spatial scale mediates the influence of habitat fragmentation on dispersal success: implications for conservation.

Theoretical Population Biology 41:315-336.

Everest, F.H., R.L. Beschta, J.S. Scrivener, K.V. Koski, J.R. Sedell, and C.J. Cederholm. 1987. Fine sediment and salmonid production: a paradox. Pages 98-142 in E. O. Salo, and T.W. Cundy editors. Streamside management: forestry and fishery interactions. Contribution Number 57. Institute of Forest Resources, University of Washington, Seattle, Washington, USA.

Fahrig, L. 1990. Simulation methods for developing general landscape-level hypotheses of single-species dynamics. In M.G. Turner and R.H. Gardner, editors. Quantitative methods in landscape ecology, the analysis and interpretation of landscape heterogeneity.

Springer-Verlag. Ecological Studies 82:438-442.

Falconer, D.S. 1989. Introduction to quantitative genetics, 3rd edition. Longman Scientific and Technical, Essex, England.

Fausch, K.D. 1988. Tests of competition between native and introduced salmonids in streams: what have we learned? Canadian Journal of Fisheries and Aquatic Sciences 45:2238-2246.

Franklin, I.E. 1980. Evolutionary change in small populations. Pages 135-150 in M.E. Soulé and B.A. Wilcox, editors. Conservation Biology: an evolutionary-ecological perspective. Sinauer Associates, Sunderland, Massachusetts, USA.

Frissell, C.A. 1993. A new strategy for watershed restoration and recovery of Pacific salmon in the Pacific Northwest. Report prepared for the Pacific Rivers Council, Eugene, Oregon, USA.

Frissell, C.A., W.J. Liss, and D. Bayles. 1993. An integrated biophysical strategy for ecological restoration of large watershed; proceedings of changing roles in water resources management and policy. Paper presented at a symposium sponsored by the American Water Resources Association, June 27-30, 1992, Seattle, Washington, USA.

Gilpin, M.E. 1987. Spatial structure and population vulnerability. Pages 125-139 in M. Soulé, editor. Viable populations for conservation. Cambridge University Press, New York, New York, USA.

Gilpin, M.E., and M.E. Soulé. 1986. Minimum viable populations: processes of species extinction. Pages 13-34 in M.E. Soulé, editor. Conservation biology: the science of scarcity and diversity. Sinauer Associates, Sunderland, Massachusetts.

Gross, M.R. 1991. Salmon breeding behavior and life history evolution in changing environments. Ecology 72(4):1180-1186.

Hanski, I. 1985. Single-species spatial dynamics may contribute to long-term rarity and commonness. Ecology 66(2):335-343.

Hanski, I. 199l. Single species metapopulation dynamics: concepts, models, and observations. Biological Journal of the Linnean Society 42:17-38.

Hanski, I., and M. Gilpin. 1991. Metapopulation dynamics: brief history and conceptual domain. Biological Journal of the Linnean Society 42:3-16.

Hobbs, R.J., and L.F. Huenneke. 1992. Disturbance, diversity and invasion: implications for conservation. Conservation Biology 6(3):324-337. 
Hynes, J.D., E.H. Brown, Jr., J H. Helle, N. Ryman, and D.A. Webster. 1981. Guidelines for the culture of fish stocks for resource management. Canadian Journal of Fisheries and Aquatic Sciences 38:1867-1876.

Labell, M. 1992. Straying patterns of coho salmon (O. kisutch) stocks from southeast Vancouver Island, British Columbia. Canadian Journal of Fisheries and Aquatic Sciences 49:1843-1855.

Lande, R. 1988. Genetics and demography in biological conservation. Science 241:1455-1460.

Leary, R.F., F.W. Allendorf, and S.H. Forbes. 1991. Conservation genetics of bull trout in the Columbia and Klamath River Drainages. Wild Trout and Salmon Genetics Laboratory Report. University of Biological Sciences, University of Montana, Missoula, Montana, USA.

Leigh, E.D. 1981. The average lifetime of a population in a varying environment. Journal of Theoretical Biology 90:213-239.

MacLean, J.A., and D.O. Evans. 1981. The stock concept, discreteness of fish stocks, and fisheries management. Canadian Journal of Fisheries and Aquatic Sciences 38:1889-1898.

Markle, D.F. 1992. Evidence of bull trout $x$ brook trout hybrids in Oregon. Pages 58-67 in P.J. Howell and D.V. Buchanan, editors; proceedings of the Gearhart Mountain bull trout workshop. Oregon Chapter of the American Fisheries Society, Corvallis, Oregon, USA.

McMahon, T.E., and J.C. Tash. 1988. Experimental analysis of the role of emigration in population regulation of desert pupfish. Ecology 69:1871-1883.

Morrison, G., and P. Barbosa. 1987. Spatial heterogeneity, population regulation, and local extinction in simulated host-parasitoid interactions. Oecologia 73:609-614.

Moyle, P.B., and G.M. Sato. 1991. On the design of preserves to protect native fishes. Pages 155-173 in W.L. Minckley and J.E. Deacon, editors. Battle àgainst extinction: native fish management in the American West. University of Arizona Press, Tucson, Arizona, USA.

Mullan, J.W., K. Williams, G. Rhodus, T. Hillman, and J. McIntyre. 1992. Production and habitat of salmonids in Mid-Columbia River tributary streams. U.S. Fish and Wildlife Service, Monograph 1.
Murphy, D.D., and B.R. Noon. 1992. Integrating scientific methods with habitat conservation planning: reserve design for northern spotted owls. Ecological Applications 2(1):3-17.

Nelson, K., and M.E. Soulé. 1987. Genetical conservation of exploited fishes. Pages 345-368 in N. Ryman and F. Utter, editors. Population genetics and fishery management. University of Washington Press, Seattle, Washington.

Nisbet, R.M., and W.S.C. Gurney. 1982. Modelling Fluctuating Populations. John Wiley \& Sons, New York, New York, USA.

Noon, B.R., and K.S. McKelvey. 1992. Stability properties of the spotted owl metapopulation in southern California. In The California spotted owl: a technical assessment of its current status. USDA Forest Service, PSW-GTR-133, Portland, Oregon, USA.

Northcote, R.G. 1992. Migration and residency in stream salmonids -- some ecological considerations and evolutionary consequences. Nordic Journal of Freshwater Research 67:5-17.

Pearson, T.D., H.W. Lamberti, L.I. Lamberti, and G.A. Lamberti. 1992. Influence of habitat complexity on resistance to flooding and resilience of stream assemblages. Transactions of the American Fisheries Society 121:427-436.

Peterman, R.M. 1977. A simple mechanism that causes collapsing stability regions in exploited salmon populations. Journal of the Fisheries Research Board of Canada 34:1130-1142.

Peterman, R.M., and M. Gatto. 1978. Estimation of functional responses of predators on juvenile salmon. Journal of the Fisheries Research Board of Canada 35:797-808.

Pulliam, H.R. 1988. Sources, sinks and population regulation. American Naturalist 132(5):652-661.

Quinn, J.F., and A. Hastings. 1987. Extinction in subdivided habitats. Conservation Biology 1:198-207.

Reeves, G.H., and J.R. Sedelll. 1992. An ecosystem approach to the conservation and management of freshwater habitat for anadromous salmonids in the Pacific Northwest. Transactions of the 57 th North American Wildlife and Natural Resources Conference 57:408-415. 
Reisenbichler, R.R., J.D. McIntyre, M.F. Solazzi, and S.W. Landino. 1992. Genetic variation in steelhead of Oregon and Northern California. Transactions of the American Fisheries Society 121:158-169.

Ricker, W.E. 1972. Heredity and environmental factors affecting certain salmonid populations. Pages 19-160 in R.C. Simon and P.A. Larkin, editors. The stock concept in Pacific Salmon. H.R. MacMillan Lectures in Fisheries. University of British Columbia Press, Vancouver, British Columbia, Canada.

Rieman, B.E., and K.A. Apperson. 1989. Status and analysis of salmonid fisheries: westslope cutthroat trout synopsis and analysis of fishery information. Idaho Department of Fish and Game, Job Performance Report, Project F-73-R-11, Subproject II, Study 1, Job 1, Boise, Idaho, USA.

Rieman, B.E, and J.D. McIntyre. 1993. Demographic and habitat requirements for conservation of bull trout. General Technical Report INT-302. U.S. Department of Agriculture, Forest Service, Intermountain Research Station, Ogden, Utah.

Rieman, B.E., and D.L. Myers. 1991. Costs, benefits, and risks of salmonid predators in kokanee waters. Idaho Department of Fish and Game, Job Completion Report, Project F-73-R-13, Subproject II, Study II, Job I, Boise, Idaho, USA.

Salwasser, H., and B.G. Marcot. 1986. Viable population planning: a planning framework for viable populations. Pages 63-71 in B.A. Wilcox, P.F. Broussard, and B.G. Marcot, editors. The management of viable populations: theory, applications and case studies. Center for Conservation Biology, Department of Biological Sciences, Stanford University, Stanford, California, USA.

Saunders, H.R., R.J. Hobbs, and C.R. Margules. 1990. Biological consequences of ecosystem fragmentation: a review. Conservation Biology 5:18-32.

Schlosser, J.J. 1982. Trophic structure reproductive success and growth rate of fishes in a natural and modified headwater streams. Canadian Journal of Fisheries and Aquatic Sciences 39:968-978.

Schlosser, JJ. 1991. Stream fish ecology: a landscape perspective. Bioscience 41:704-712.

Sedell, J.R., G.H. Reeves, F.R. Hauer, J.A. Stanford, and C.P. Hawkins. 1990. Role of refugia in recovery from disturbances: modern fragmented and disconnected river systems. Environmental Management 14:711-724.

Shaffer, M.L. 1987. Minimum viable populations; coping with uncertainty. Pages 69-86 in M. E. Soulé, editor. Viable Populations for Conservation. Cambridge University Press, Cambridge, England.

Shaffer, M.L. 1991. Population viability analysis. Pages 107-118 in D. J. Decker, M.E. Krasny, G.R. Goff, C.R. Smith, and D.W. Gross, editors. Challenges in the conservation of biological resources. Westview Press, Boulder, Colorado, USA.

Shaffer, M.L., and F.B. Samson. 1985. Population size and extinction: a note on determining critical population sizes. The American Naturalist 125:144-151.

Sheldon, A.L. 1988. Conservation of stream fishes: patterns of diversity, rarity, and risk. Conservation Biology 2(2):149-156.

Simon, R.C. 1972. Gene frequency and the stock problems. Pages 161-169 in R.C. Simon and P.A. Larkin, editors. The stock concept in Pacific salmon. H.R. MacMillan Lectures in Fisheries. University of British Columbia, Vancouver, British Columbia, Canada.

Sjogren, P. 1991. Extinction and isolation gradients in metapopulations: the case of the pool frog (Rana lessonae). Biological Journal of the Linnean Society 42:135-147.

Soulé, M.E. 1987. Where do we go from here? Pages 175-183 in M.E. Soulé, editor. Viable Populations for Conservation. Cambridge University Press, Cambridge, England.

Stacey, P.B., and M. Taper. 1992. Environmental variation and the persistence of small populations. Ecological Applications 2(1):18-29.

Titus, R.G., and H. Mosegaard. 1992. Fluctuating recruitment and variable life history of migratory brown trout Salmo trutta in a small unstable stream. Journal of Fish Biology 41:239-255.

Wright, S. 1993. Fishery management of wild Pacific salmon stocks to prevent extinctions. Fisheries 18(5):3-4.

Yount, J.D., and G.J. Niemi. 1990. Recovery of lotic communities and ecosystems from disturbance -- a narrative review of case studies. Environmental Management 14(5):547-569. 
The United States Department of Agriculture (USDA) prohibits discrimination in its programs on the basis of race, color, national origin, sex, religion, age, disability, political beliefs and marital or familial status. (Not all prohibited bases apply to all programs.) Persons with disabilities who require alternative means for communication of program information (braille, large print, audiotape, etc.) should contact the USDA Office of Communications at (202) 720-5881 (voice) or (202) 720-7808 (TDD).

To file a complaint, write the Secretary of Agriculture, U.S. Department of Agriculture, Washington, D.C. 20250, or call (202) $720-7327$ (voice) or (202) 720-1127 (TDD). USDA is an equal employment opportunity employer.

The use of trade, firm or corporation names in this publication is for the information and convenience of the reader. Such use does not constitute an official endorsement or approval by the U.S. Department of Agriculture or any product or service to the exclusion of others that may be suitable. 


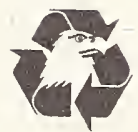

